\title{
Proceeding
}

Performance Analysis Workshop, 2 - 5 April 2013, Alicante, Spain

\section{Water polo women's pattern tactical experience of an italian team}

\author{
SALVATORE NAPOLITANO , DANIELA TURSI, GAETANO RAIOLA \\ Department of Human, Philosophical and Education Sciences (DISUFF) University of Salerno, Italy
}

\begin{abstract}
Napolitano S, Tursi D, Raiola G. Water polo women's pattern tactical experience of an italian team. J. Hum. Sport Exerc. Vol.8, No. Proc3, pp. S660-S670, 2013. In water polo lacks a codified methodology for tactics training, which is thus only left to coach's discretion. Nine women water polo matches, during season 2011/2012 (Italian female Serie A1), have been analyzed by a water polo coach, helped by a statistician and a performance analyst. Purpose of the analysis process was to identify single events during the matches, to examine the tactical pattern implemented in this events, to obtain by the coach an evaluation on tactical pattern compliance and then to put this compliance in relation to event's outcome. Aim of the work is to verify the efficacy of different attack patterns, when they were well-performed, in order to create a codified methodology for teaching water polo through tactics. The research approach is integrated and consists of 3 distinct methods: case study (9 matches of the Italian Serie A1 Women's Championship, season 2011/2012, played by the Volturno sc) for the analysis of matches, action research method for coach contribution, and theoretical-argumentative method to deduce a theoretical framework in which define the data processing. The research team examined matches with Dartfish TeamPro, isolating single keyframes relative to attack events, identifying the implemented attack pattern, then the coach expressed an evaluation on attack pattern compliance. The results showed a general efficacy of tactical patterns (when they are well performed), but showed significant differences within correlation coefficients of single patterns, confirming the need for developing a common methodology for teaching water polo through tactics. Key words: VIDEOANALYSIS, WATER POLO TACTIS, PERFORMANCES.
\end{abstract}

Corresponding author. Salvatore Napolitano, Via Achille D'Orsi 13, Napoli, Italy.

E-mail: salvatorenapolitano1@alice.it

Performance Analysis Workshop, 2 - 5 April 2013, Alicante, Spain

JOURNAL OF HUMAN SPORT \& EXERCISE ISSN 1988-5202

(c) Faculty of Education. University of Alicante

doi:10.4100/jhse.2013.8.Proc3.12 


\section{INTRODUCTION}

This pilot work represents an attempt to develop methods and consequential tools to analyze, and then train, tactical water polo side, knowing that

"the coaches of team sports analyze matches and performances of team and opposing teams to get useful data in coaching" (Hughes \& Franks, 2008) and that,

"currently, the process of training, its organization, and teaching methodology need more knowledge on the qualitative aspects of sports performance (Schmidt \& Wrisberg, 2008)".

Nine women water polo matches, during season 2011/2012 (Italian Serie A1), have been analyzed by a water polo coach, helped by a statistician and a performance analyst.

Purpose of the analysis process was:

- to identify single events during the matches,

- to examine the tactical patterns implemented in these events,

- to obtain by the coach an evaluation on tactical pattern compliance and then

- to put this compliance in relation to event's outcome.

Aim of the work is to verify the efficacy of different attack patterns, when they were well-performed, in order to create a codified methodology for teaching water polo through tactics. The data, collected via Dartfish TeamPro Software, were analyzed trough a "Water polo Tactics Analyzer" software, developed as a webbased application at University of Salerno and released under GPL license, which returned basic descriptive statistics and the correlation coefficient of each pattern with events outcomes.

The results show a positive and statistically significant correlation coefficient between tactical compliance and events outcome, and highlight the need for developing a common methodology for teaching water polo through tactics, confirming once again that

"the practical value of performance analysis is that well-chosen performance indicators highlight good and bad techniques or team performances (Hughes)".

\section{MATERIAL AND METHODS}

The research approach is integrated and consists of 3 distinct methods:

- case study (9 matches of the Italian Serie A1 Women's Championship, season 2011/2012, played by the Volturno s.c.) for the analysis of matches,

- action research method for coach contribution,

- and theoretical-argumentative method to deduce a theoretical framework in which define the data processing.

\section{Participants}

Team Volturno S.C. (9 matches of the Italian Serie A1 Women's Championship, season 2011/2012).

Procedures

The survey of data is entrusted to performance analysis, carried out with the help of a water polo coach, a statistician and a performance analyst. 
The assessment of compliance for the tactical patterns is entrusted to the coach, on the basis of the video analysis-aided confrontation of attack pattern design against attack pattern effectively implemented during match. The research team examined matches with Dartfish Team Pro, isolating single key frames relative to attack events, identifying the implemented attack pattern, then the coach expressed an evaluation on attack pattern compliance.
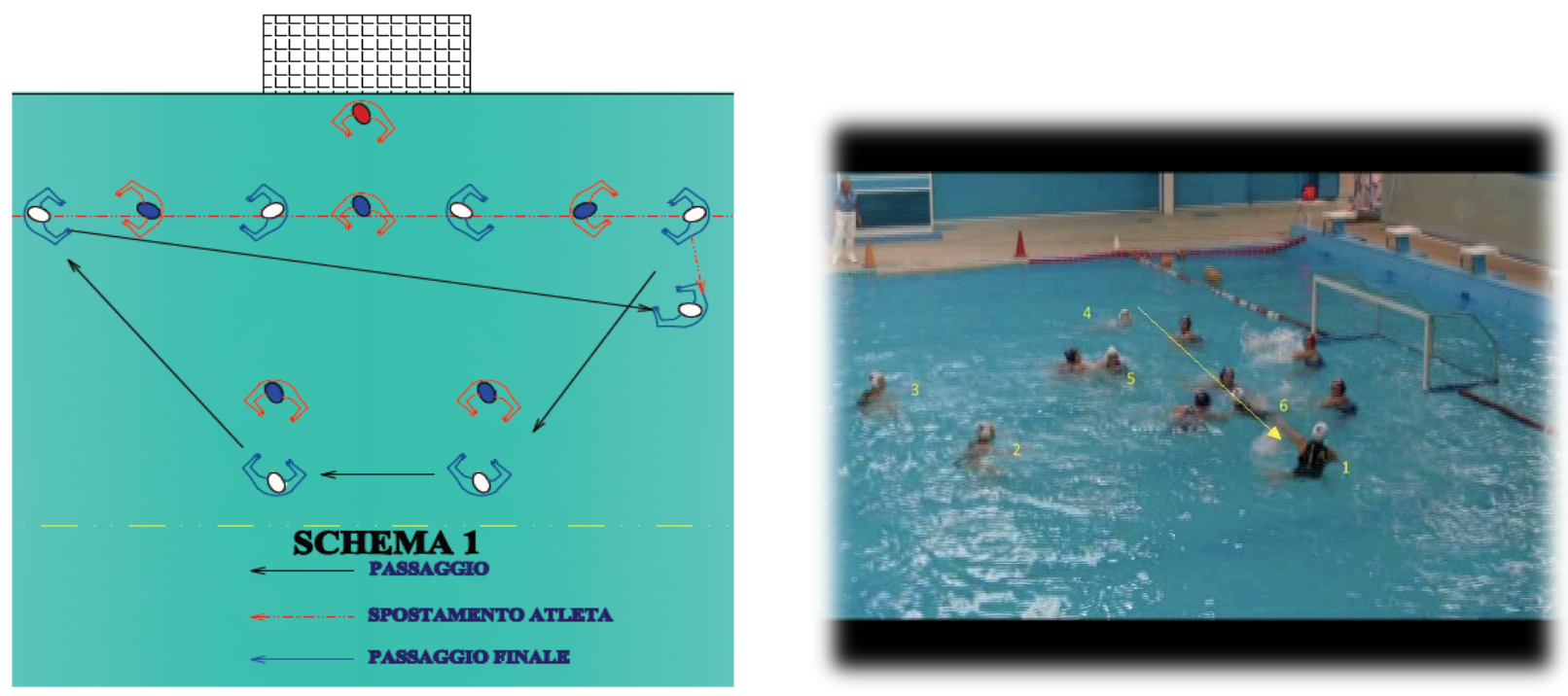

Figure 1. Confrontation between pattern design and effectively implemented pattern during match for attack pattern named "schema1"

A spreadsheet containing, for each row, the match id, the event id, the attack pattern id, the coach's evaluation (compliant/non compliant) and the event outcome (goal / non goal) was filled.

This data sheet is processed through the "water polo Tactics analyzer software", which produces basic descriptive statistics and the correlation coefficient of each well-implemented attack pattern with events outcomes. In total, 7 attack patterns on 73 events during 9 matches were analyzed. The analyzer software output is discussed by the research team, with consciousness of internal validity, allowed by action research method, of this kind of qualitative analysis.

Materials

Two cameras to film the games

One laptop for analyze end prepare video lessons to show by projector to players during all meetings. Kinovea software was used for select most important part of videos and select the frames.

\section{RESULTS}

An evaluation table was constructed by combining, for each single event, the Boolean evaluation of the coach on the compliance of patterns with the event final outcome.

Here are reported:

- Confrontations of pattern design with Dartfish screenshot of pattern implemented during game;

- Basic descriptive statistics (occurrence of single patterns on events total, occurrence of "wellperformed pattern" on events total, etc...); 

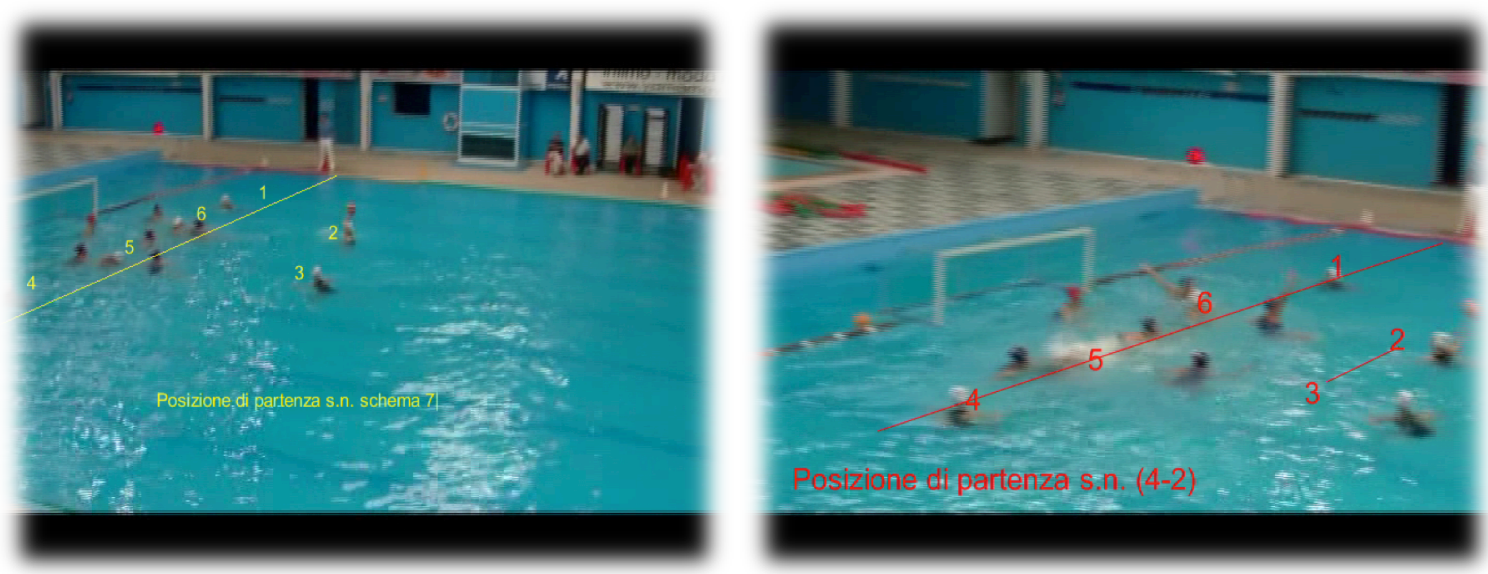

Figure 2. Starting grid
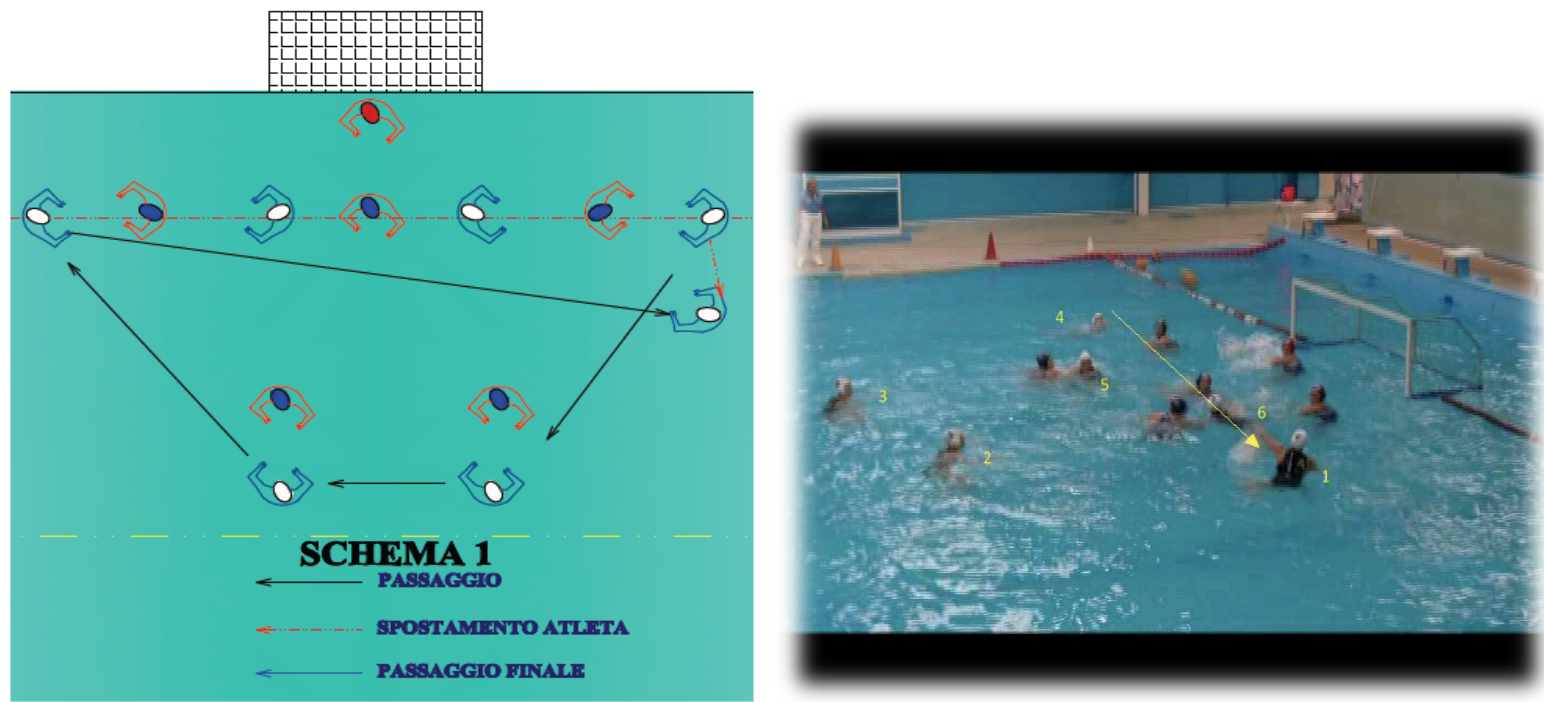

Figure 3. Design of pattern named «schema1» Pattern «schema1» Screenshot


Figure 4. Design of pattern named «schema2» Pattern «schema2» Screenshot 

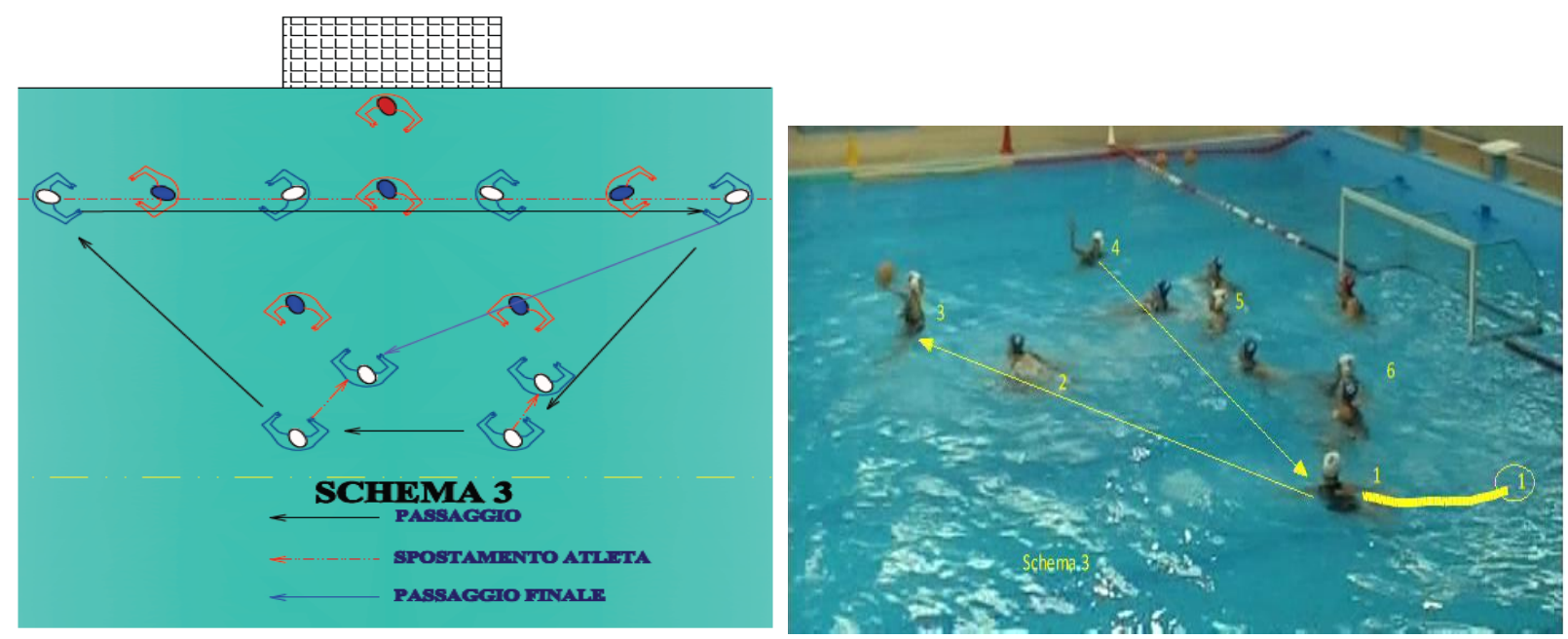

Figure 5. Design of pattern named «schema3» Pattern «schema3» Screenshot
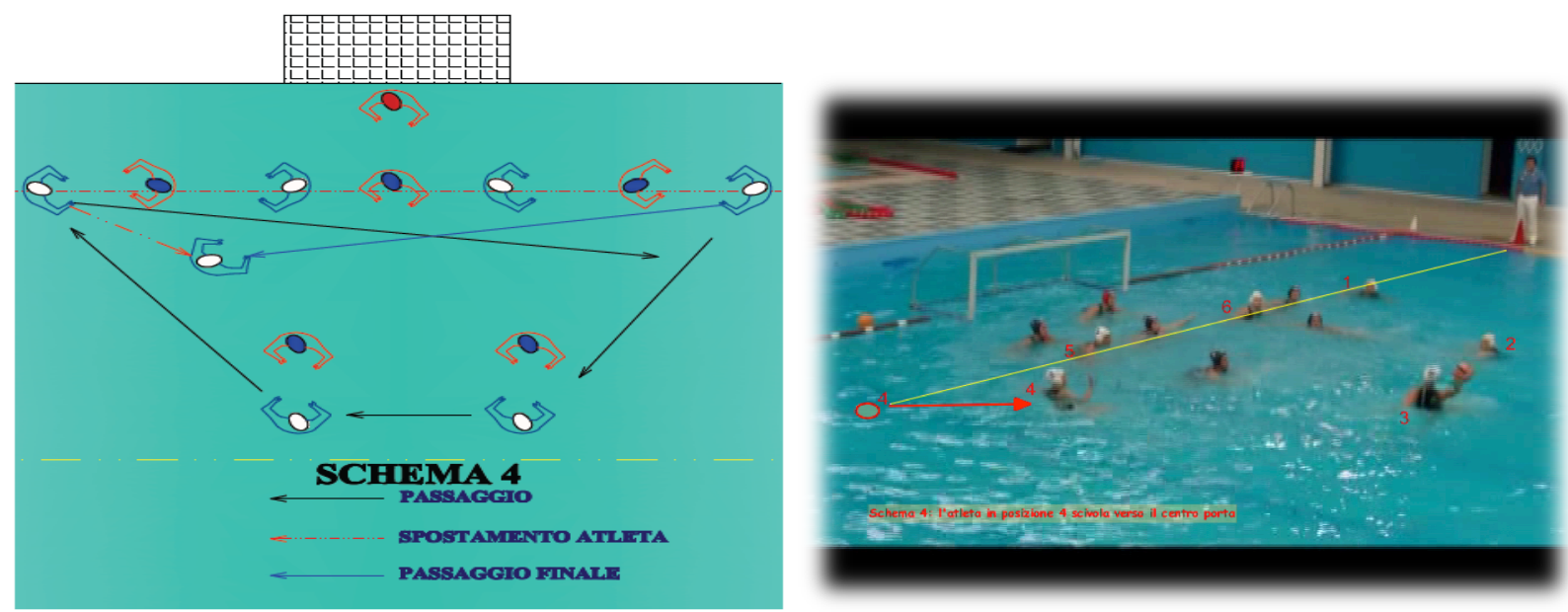

Figure 6. Design of pattern named «schema4» Pattern «schema4» Screenshot
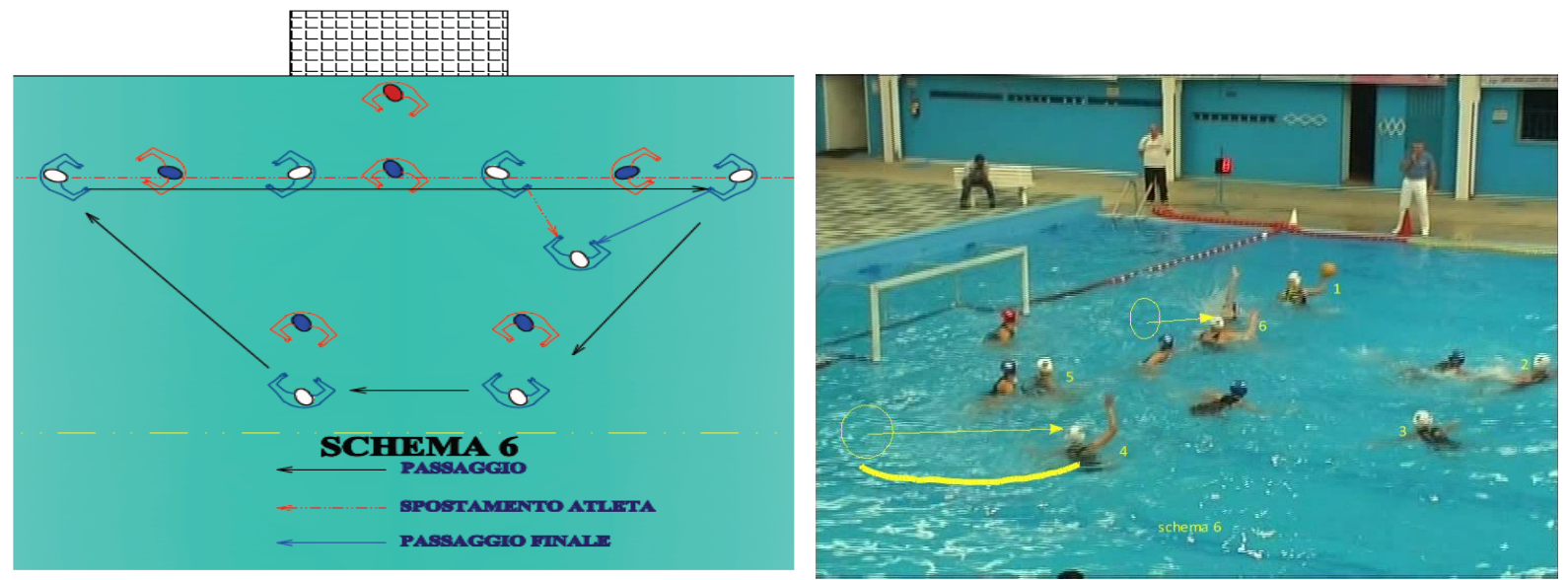

Figure 7. Design of pattern named «schema6» Pattern «schema6» Screenshot 

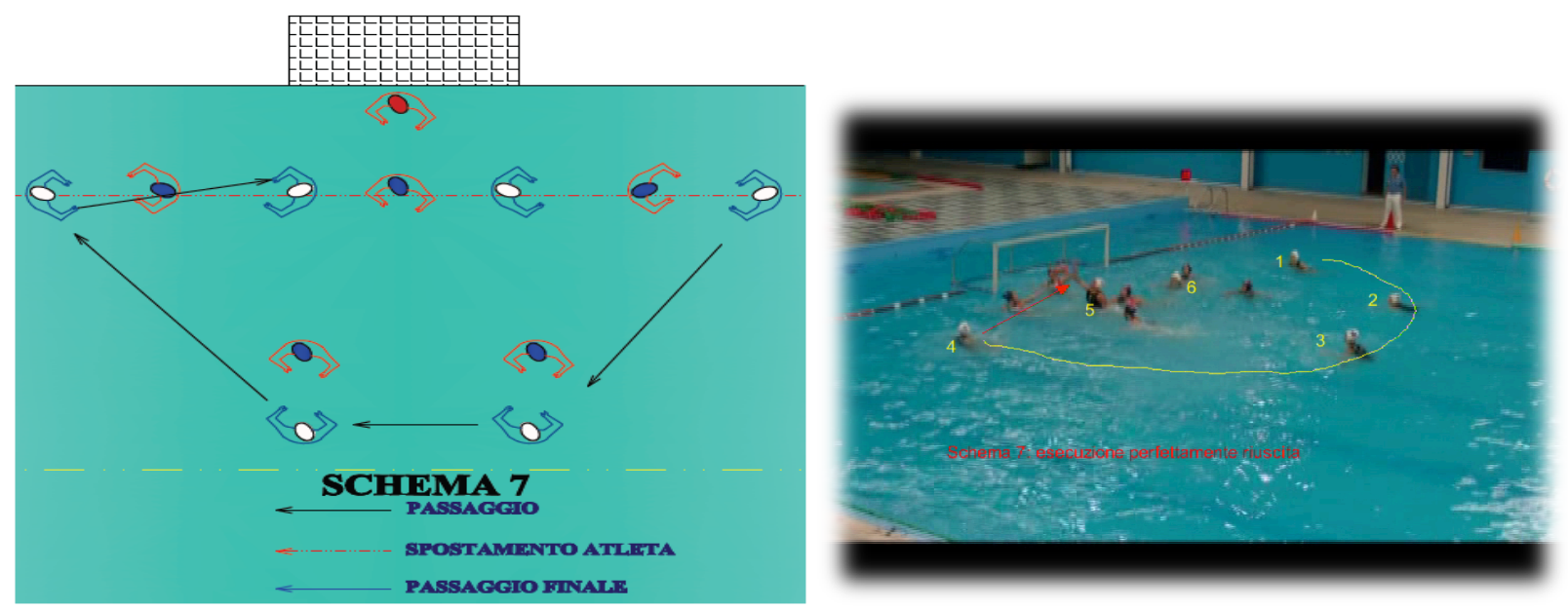

Figure 8. Design of pattern named «schema7» Pattern «schema7» Screenshot
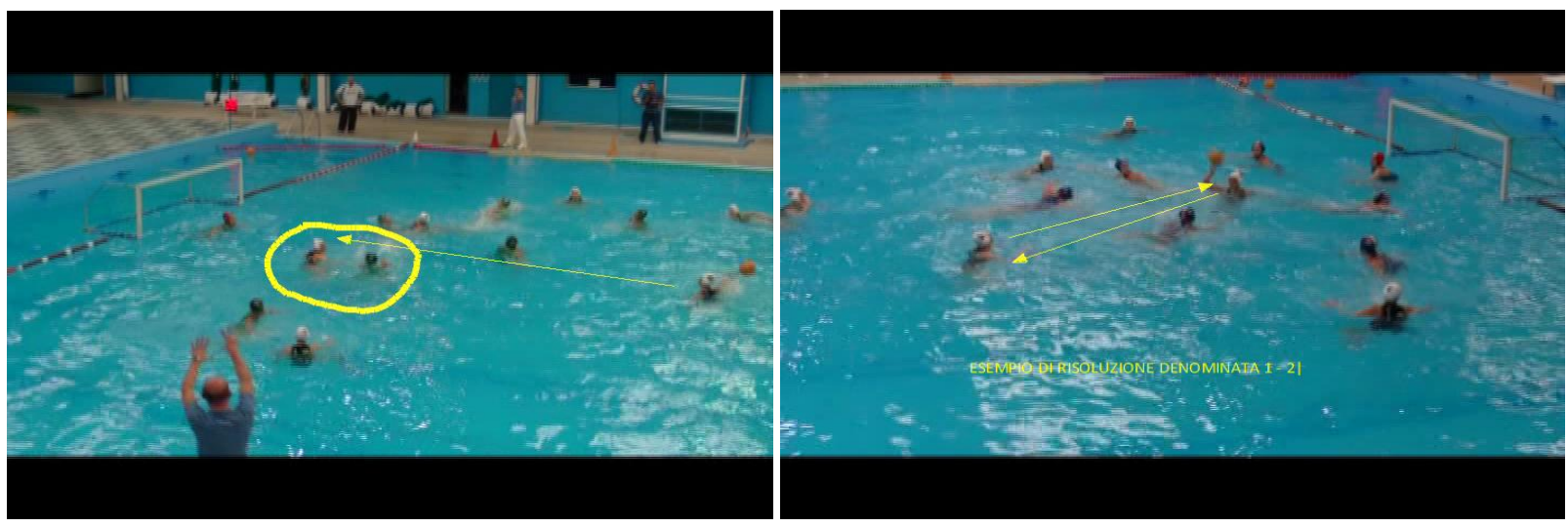

Figure 9. Pattern «schema 1-2» Screenshot

Table 1. Patterns occurrence - 7 attack patterns on 73 events during 9 matches.

\begin{tabular}{lccc} 
Pattern & Occurrence & Compliant Occurrence & Goals \\
\hline Schema_1 & 15 & 10 & 6 \\
schema_2 & 6 & 3 & 3 \\
schema_3 & 8 & 3 & 2 \\
schema_4 & 8 & 4 & 3 \\
schema_7 & 25 & 21 & 13 \\
schema_1.2 & 7 & 5 & 1 \\
schema_6 & 4 & 4 & 2 \\
\hline
\end{tabular}




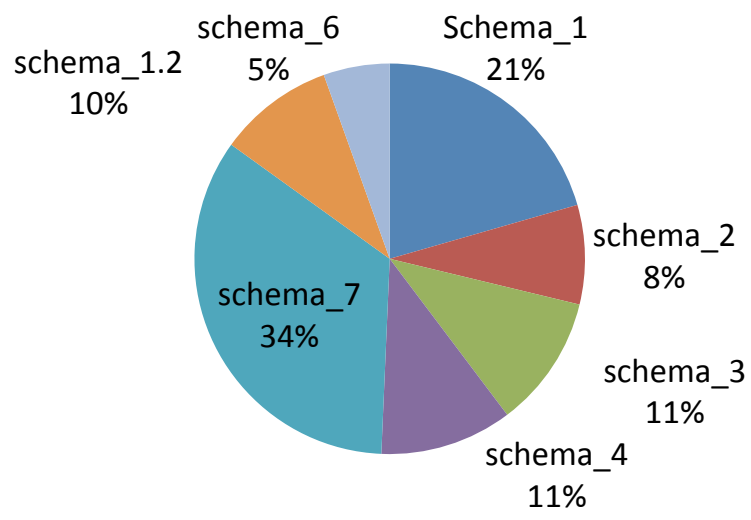

Figure 10. Patterns occurrences - 7 attack patterns

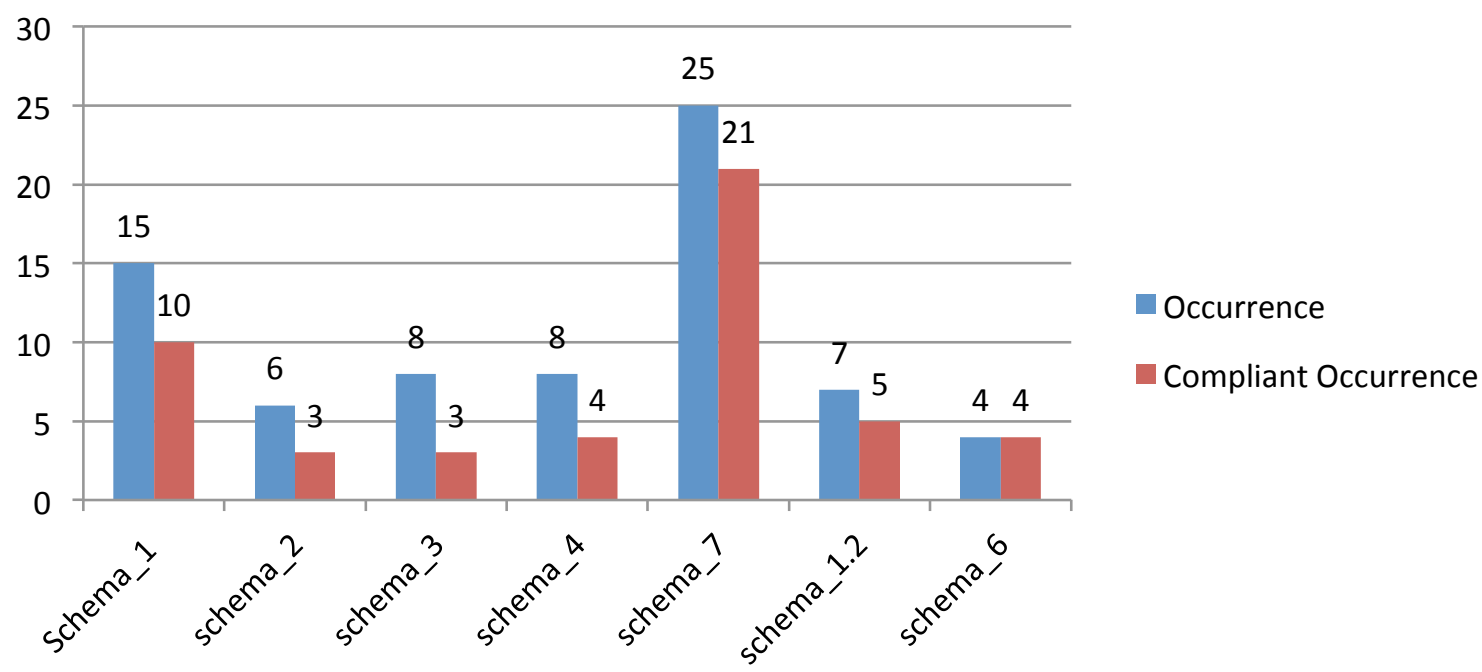

Figure 11. Well performance patterns occurrence

Tables 2. Schema 1

\begin{tabular}{llll} 
Match & Total occurrence & Well performed & goals \\
\hline volturno vs orizzonte ct & 2 & 1 & 0 \\
volturno vs fiorentina fi & 0 & 0 & 0 \\
volturno vs ortiga sr & 3 & 2 & 1 \\
volturno vs firenze pn & 2 & 2 & 2 \\
volturno vs padova & 1 & 0 & 0 \\
volturno vs messina & 1 & 1 & 1 \\
volturno vs imperia & 2 & 1 & 1 \\
volturno vs pro recco & 2 & 2 & 0 \\
volturno vs bologna & 2 & 1 & 1 \\
\hline
\end{tabular}


Tables 3. Schema 2

\begin{tabular}{lccc} 
Match & Total occurrence & Well-performed & goals \\
\hline volturno vs orizzonte ct & 2 & 1 & 1 \\
volturno vs fiorentina fi & 2 & 1 & 1 \\
volturno vs ortiga sr & 0 & 0 & 0 \\
volturno vs firenze pn & 0 & 0 & 0 \\
volturno vs padova & 0 & 0 & 0 \\
volturno vs messina & 0 & 0 & 0 \\
volturno vs imperia & 0 & 0 & 0 \\
volturno vs pro recco & 0 & 0 & 0 \\
volturno vs bologna & 2 & 1 & 1 \\
\hline
\end{tabular}

Tables 4. Schema 3

\begin{tabular}{lccc} 
Match & Total occurrence & Well performed & goals \\
\hline volturno vs orizzonte ct & 1 & 1 & 1 \\
volturno vs fiorentina fi & 1 & 1 & 1 \\
volturno vs ortiga sr & 0 & 0 & 0 \\
volturno vs firenze pn & 1 & 0 & 0 \\
volturno vs padova & 1 & 0 & 0 \\
volturno vs messina & 3 & 1 & 0 \\
volturno vs imperia & 0 & 0 & 0 \\
volturno vs pro recco & 0 & 0 & 0 \\
volturno vs bologna & 1 & 0 & 0 \\
\hline
\end{tabular}

Table 5. Summary Table

\begin{tabular}{ccc} 
Pattern & stderr & correlation (well performed patterns /goals \\
\hline schema_1 & 0.43678760300431 & 0.76332253361379 \\
schema_2 & 0 & 1 \\
schema_3 & 0.30860669992418 & 0.75592894601845 \\
schema_4 & 0.11624763874382 & 0.98810492932246 \\
schema_7 & 0.54916964736528 & 0.22360679774998 \\
schema_1.2 & 0.34684398780965 & 0.22941573387056 \\
schema_6 & 0.37796447300923 & 0.5976143046672 \\
\hline
\end{tabular}


Stder $=0,64-$ corr $=0,53$



Figure 12. Linear regression schema 1



Figure 13. Linear regression schema 2 


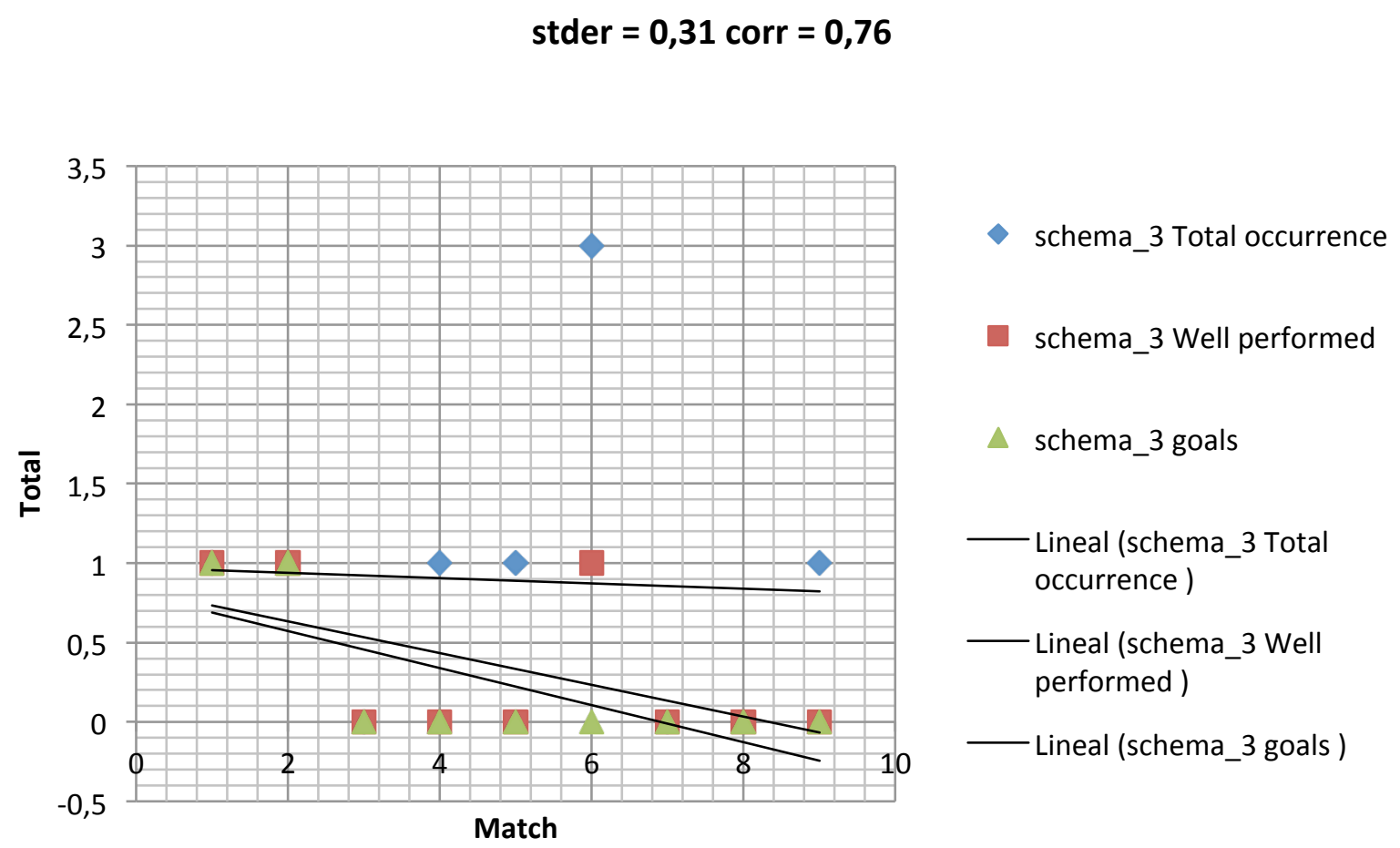

Figure 14. Linear regression schema 3

\section{CONCLUSIONS}

The results showed a general efficacy of tactical patterns (when they are well performed), but showed significant differences within correlation coefficients of single patterns, knowing that

"the correlation coefficient indicates magnitude or amount of a relationship and the direction of relationship" [Morrow, Jackson].

A more consistent data base is needed, in order to establish direct, evident and general relationship between so calculated coefficient and pattern efficacy, and the research team is conscious of internal validity of this kind of qualitative analysis, which can't extend, without adjustments, to other teams.

Although, analysis results represents a tool for the coach, in order to better train team in next season, which were an aim of action research, and showed a general trend on tactical pattern efficacy, which will be deeply investigated in future works.

\section{REFERENCES}

1. HUGHES M, FRANKS I. The essentials of performance analysis: an introduction. Taylor \& Francis e-Library, 2007.

2. HUGHES M. Notational analysis - a mathematical perspective. Int J Perform Anal Sport. 2004; 4(2):97-139.

3. HUGHES MD, FRANKS I. Notational Analysis of Sport: Systems for Better Coaching and Performance in Sport. Routledge, 2008. 
4. RAIOLA G, DI TORE A. Applied Regression Analysis: study about the incidence of communication skills on the results of volleyball matches over a full season in Scientific Report Series Physical Education And Sport 1/2011. Pitesti: Romania, 2011.

5. SCHMIDT R, WRISBERG C. Motor learning and Performance. Human Kinetics, 2008. 